ISSN: 09067590

doi: $10.1111 /$ ecog.01245

\title{
MODELLING THE NICHE FOR A MARINE VERTEBRATE: A CASE STUDY INCORPORATING BEHAVIOURAL PLASTICITY, PROXIMATE THREATS AND CLIMATE CHANGE
}

\author{
Pikesley, S.K. ${ }^{\mathrm{ab}}$, Broderick, A.C. ${ }^{\mathrm{a}}$, Cejudo, D. ${ }^{\mathrm{c}}$, Coyne, M.S. ${ }^{\mathrm{d}}$, Godfrey, M.H. ${ }^{\mathrm{e}}$, Godley, B.J. ${ }^{\mathrm{a}}$, Lopez, \\ P. ${ }^{f}$, López-Jurado, L.F.g , Elsy Merino, S. ${ }^{\text {, }}$, Varo-Cruz, N.g, Witt, M.J. ${ }^{\text {, }}$, Hawkes, L.A. ${ }^{\text {a }}$
}

\author{
a Centre for Ecology and Conservation, College of Life and Environmental Sciences, Univ. of Exeter, Penryn, Cornwall, United \\ Kingdom \\ b Environment and Sustainability Inst., Univ. of Exeter, Cornwall, United Kingdom \\ c Cabo Verde Natura, Sal-Rei, Boavista, Cape Verde \\ d Seaturtle.org, 1 Southampton Place, Durham, NC, United States \\ e North Carolina Wildlife Resources Commission, 1507 Ann Street, Beaufort, NC, United States \\ f Bios.CV, Sal-Rei, Boavista, Cape Verde \\ g Depto de Biología, Univ. de Las Palmas de G.C. Campus de Tafira, Las Palmas de Gran Canaria, Gran Canaria, Spain \\ h Inst. Nacional de Desenvolvimento das Pescas, Mindelo, Sao Vicente, Cape Verde
}

\begin{abstract}
The integration of satellite telemetry, remotely sensed environmental data, and habitat/environmental modelling has provided for a growing understanding of spatial and temporal ecology of species of conservation concern. The Republic of Cape Verde comprises the only substantial rookery for the loggerhead turtle Caretta caretta in the eastern Atlantic. A size related dichotomy in adult foraging patterns has previously been revealed for adult sea turtles from this population with a proportion of adults foraging neritically, whilst the majority forage oceanically. Here we describe observed habitat use and employ ecological niche modelling to identify suitable foraging habitats for animals utilising these two distinct behavioural strategies. We also investigate how these predicted habitat niches may alter under the influence of climate change induced oceanic temperature rises. We further contextualise our niche models with fisheries catch data and knowledge of fisheries 'hotspots' to infer threat from fisheries interaction to this population, for animals employing both strategies. Our analysis revealed repeated use of coincident oceanic habitat, over multiple seasons, by all smaller loggerhead turtles, whilst larger neritic foraging turtles occupied continental shelf waters. Modelled habitat niches were spatially distinct, and under the influence of predicted sea surface temperature rises, there was further spatial divergence of suitable habitats. Analysis of fisheries catch data highlighted that the observed and modelled habitats for oceanic and neritic loggerhead turtles could extensively interact with intensive fisheries activity within oceanic and continental shelf waters of northwest Africa. We suggest that the development and enforcement of sustainable management strategies, specifically multi-national fisheries policy, may begin to address some of these issues; however, these must be flexible and adaptive to accommodate potential range shift for this species.
\end{abstract}

